Dicle University Journal of Engineering (DUJE)

web: http://dergipark.gov.tr/dumf

Araştırma Makalesi / Research Article

\title{
Endüstri 4.0 Uyumlu DC Wattmetre Tasarımı
}

\section{Industry 4.0 Compatible DC Wattmeter Design}

\author{
Ayetül Gelen ${ }^{*}$, Selçuk Barış Onur ${ }^{2}$ \\ ${ }^{1}$ Bursa Teknik Üniversitesi, Elektrik Elektronik Mühendisliği Bölümü, Bursa, ayetul.gelen@btu.edu.tr \\ ${ }^{2}$ Bursa Teknik Üniversitesi, Elektrik Elektronik Mühendisliği Bölümü, Bursa, selcukbarisonur@gmail.com
}

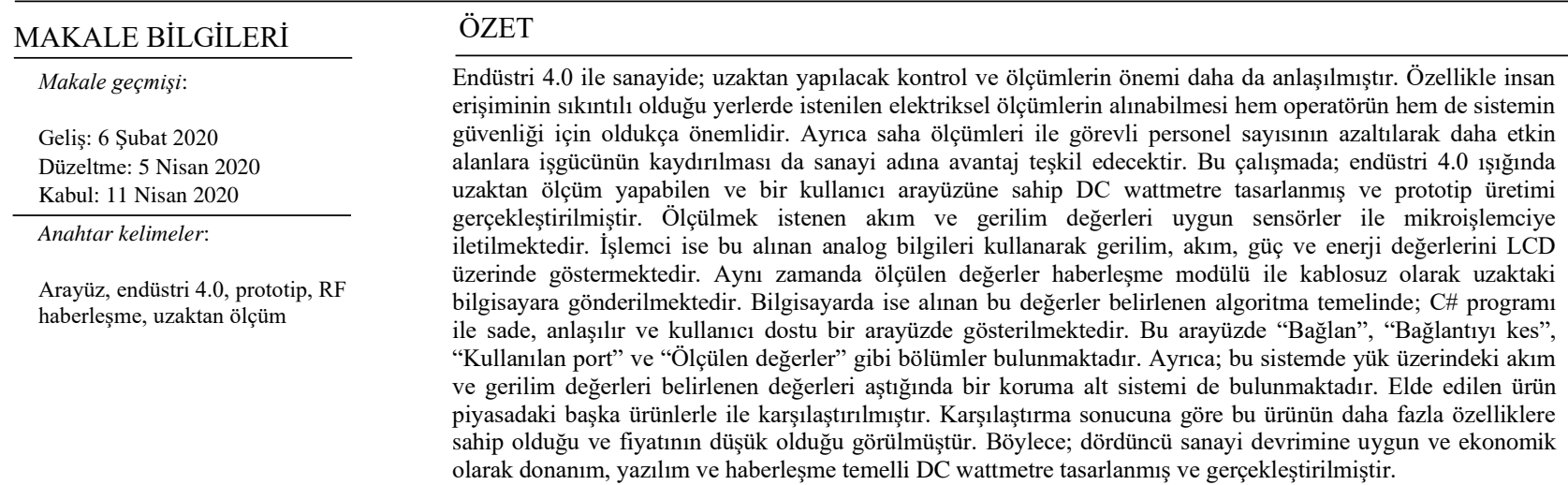

Doi: $10.24012 /$ dumf. 685760

\begin{tabular}{|c|c|}
\hline ARTICLE INFO & ABSTRACT \\
\hline & \multirow{6}{*}{$\begin{array}{l}\text { With Industry } 4.0 \text {, the importance of remote control and measurements in the industry has been further } \\
\text { understood. It is very important for security of both the operator and the system to be able to take the desired } \\
\text { electrical measurements, especially in areas where human access is troubled. Besides, reducing the number of } \\
\text { personnel assigned to field measurements and shifting them to more effective areas will be an advantage for the } \\
\text { industry. In this study; DC wattmeter capable of remote measurement in the light of industry } 4.0 \text { and has a user } \\
\text { interface was designed and prototyped. Current and voltage values to be measured are transmitted to a } \\
\text { microprocessor by appropriate sensors. The processor displays the voltage, current, power and energy values on } \\
\text { the LCD. At the same time, the measured values are transmitted wirelessly via the communication module to the } \\
\text { remote computer. On the computer, these values are shown in a simple, understandable and user-friendly } \\
\text { interface with the C\# program. This interface includes sections such as "connect", "disconnect", "port used" and } \\
\text { "measured values". Also; this system has a protection subsystem when the current-voltage values on the load } \\
\text { exceed the specified values. The product was compared with other products and it has more features and its price } \\
\text { is low. Thus; a DC wattmeter based on hardware-software-communication was designed economically and } \\
\text { under the fourth industrial revolution. }\end{array}$} \\
\hline Received: 6 February 2020 & \\
\hline Revised: 5 April 2020 & \\
\hline Accepted: 11 April 2020 & \\
\hline Keywords: & \\
\hline $\begin{array}{l}\text { Industry } 4.0 \text {, interface, } \\
\text { prototype, RF communication, } \\
\text { remote measurement. }\end{array}$ & \\
\hline
\end{tabular}

* Sorumlu yazar / Correspondence

Ayetül GELEN

$\triangle$ ayetul.gelen@btu.edu.tr 


\section{Giriș}

Endüstri 4.0 devrimine göre fabrikadaki cihazlar mümkün mertebe birbirleri ile haberleşebilmeli ve bu süreç insanlar tarafindan anlaşılabilir olmalıdır. İnsan ve bilgisayar etkileşiminin yollarından birisi de aracı bir kullanıcı arayüzü kullanmaktır. Böylelikle sistemin işlevselliğinin artması hedeflenmektedir [1]

Herhangi bir güç sisteminin güvenilir çalışması için ölçüm önemlidir. Özellikle gerilim ve akım ölçümleri çoğu zaman çeşitli koruma cihazları, tarife amaçları ve denetleyiciler için girdi olarak kullanılmaktadır. Geleneksel gerilim ölçümleri yapılırken ölçüm cihazı doğrudan ölçülen devreye bağlanmaktadır. $\mathrm{Bu}$ nedenle, aletlerin devrede normal ve anormal gerilimlere dayanacak şekilde yalıtılması gerekmektedir. Hem pano tipi hem de el ile yapılan ölçümlerde izolasyon oldukça önemlidir. Yapılacak izolasyonun seviyesi arttıkça cihazların büyüklüğü, ağırlığı ve maliyeti de artacaktır. Öyle ki sistem geriliminin artması da bu etkenlere katkı sağlayacaktır [2].

Cataliotti vd. [3] DAQ NI USB 9239 kullanarak PC-tabanlı bir wattmetre tasarlamışlardır. Ancak bu tasarım sadece $\mathrm{AC}$ güç ölçümü yapmaktadır ve modüler, monte edilebilir bir cihaz değildir. Jovanoviç [4] ise mikrodenetleyici temelli akım ve gerilim ölçüm sonucunu da gösteren wattmetre tasarlamış ve gerçekleştirmiştir. Ancak bu cihaz kablolu olarak RS232 ile haberleşmekte ve sadece $\mathrm{AC}$ büyüklükleri ölçmektedir. DC wattmetre çalışmaları literatürde yeterince mevcut değildir. Dewolf ve Michael [5] özellikle DC motor giriş gücünü ölçebilmek için elektronik wattmetre prototipi geliştirmişlerdir. Bu cihazın akım ve gerilimi sınırlama özellikleri bulunurken haberleşme, kullanıcı arayüzü, modülerlik vb. özellikleri bulunmamaktadir.

$\mathrm{Bu}$ çalışmanın motivasyon kaynaklarından biri; günümüzde büyük önem arz eden endüstri 4.0 başka bir deyişle "dijital dönüşüm” kapsamında, uzaktan erişilebilen ve anlaşılabilir bir kullanıcı arayüzüne sahip olan DC wattmetre tasarlamaktır. İkincil olarak ta bu uzaktan izleme kabiliyeti ile sanayide sıklıkla kullanılan DC elektrik parametrelerinin el ile ölçümlerinin yapılması durumunda kullanıcıyı, cihazı ve sistemi koruma yöntemlerinden biri olan izolasyon konusunda indirgeme yapabilmektir.
$\mathrm{Bu}$ indirgeme ise bu tür cihazların özellikle daha hafif ve ekonomik olmasinı da beraberinde getirecektir. En önemlisi de yerli ve dişa bağımlılığ1 azaltan bir ürün elde edilmiş olacaktır.

$\mathrm{Bu}$ çalışmanın yenilik tarafi; mevcutta kullanılan DC wattmetrelerin özelliklerine ek olarak uzaktan, kablosuz bir haberleşme protokolü ile bilgisayardan izlenebilme imkânına sahip, fiyat/performans oranı düşük olan bir cihaz olmasıdır. Böylece minimum insan gücü ile aynı işler yapılabilecektir ki bu da endüstri 4.0 '’n doğasına uygun olacaktır. $\mathrm{Bu}$ çalışmanın temel tasarım kısımları (detayları olmaksizın) sadece özet metin olarak uluslararası bir konferansta sunulmuştur [6]. Bu makalede ise enerji ölçümü, operatörün akım ve gerilim değerlerine sınır koyabilmesi vb. özellikler eklenerek genişletilmiş ve geliştirilmiş olup prototip üretim aşamaları, devre şemaları, algoritması, uygulama sonuçları ve görselleriyle birlikte açık bir şekilde ortaya konulmuştur.

\section{Materyal ve Metot}

$\mathrm{Bu}$ çalışmada cihazın ekranında görülen, ölçülen gerilim, akım, güç ve enerji değerlerini kullanıcının bir arayüz vasıtası ile uzaktan da görerek acil müdahale edilmesi gereken bir durum olduğu zaman gereken işlemlerin hızlı bir şekilde hayata geçirilmesi amaçlanmaktadır. Ayrıca kullanılan sigortanın haricinde mikroişlemci temelli koruma da yapılmaktadır. Böylelikle personel ve sistem güvenliğine de katkı sağlanmış olacaktır.

Çalışma kapsamında ölçülmek istenen akım ve gerilim değerlerini değerlendirmek ve arayüze katkı sağlamak için işlemci olarak Ardunio kullanılmıștır. Arduino 5 V'luk çalıșma gerilimine, toplam 16 adet dijital giriş/çıkış pinine ve 6 adet analog giriș pinine sahip bir işlemcidir [7, 8]. Akım değerleri; $\pm 3.2 \mathrm{~A}$ aralığında akım ölçümü, 26 V'a kadar gerilim ölçümü yapabilen Șekil 1a'da gösterilen INA219 sensörü ile alınmaktadır. INA219 sensörü I2C protokolü ile haberleşebilmektedir [9]. Arduino için yapılan yazılım ile bu alınan ölçüm bilgileri güç ve enerji değerine de dönüştürülerek gerilim, akım, güç ve enerji değerleri Șekil 1b'de görülen $2 \times 16$ LCD üzerinde gösterilmektedir. Bu kısım doğrudan cihaz üzerinden okuma yapılan kisımdir. 

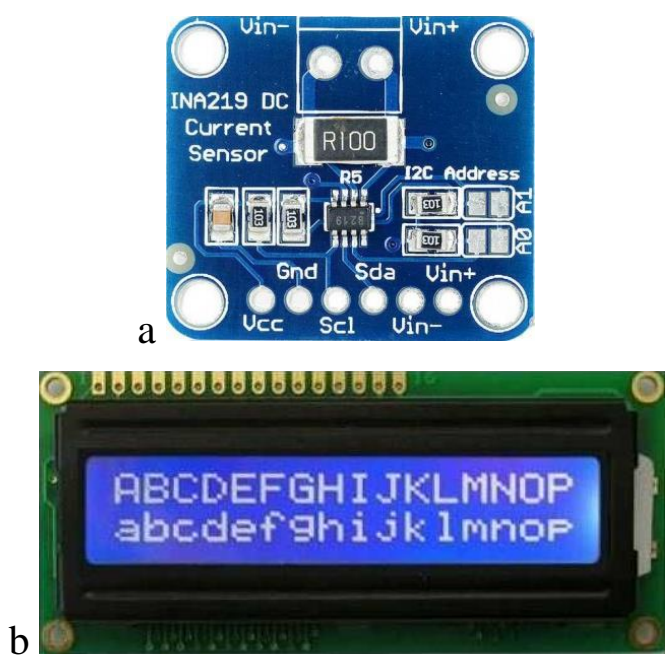

Şekil 1. a) INA219 b) LCD

Figure 1. a) INA219 b) LCD

Uzaktan haberleşme amacı ile kullanılan nRF24L01 modülünde; Nordic firmas1 tarafından geliştirilen $2.4 \mathrm{GHz}$ frekans bandında hem alıcı hem de verici olarak çalışan dijital, radyo frekans kablosuz haberleşme çipi bulunmaktadır [10]. Bu çipe ait görsel Şekil 2'de verilmiştir.

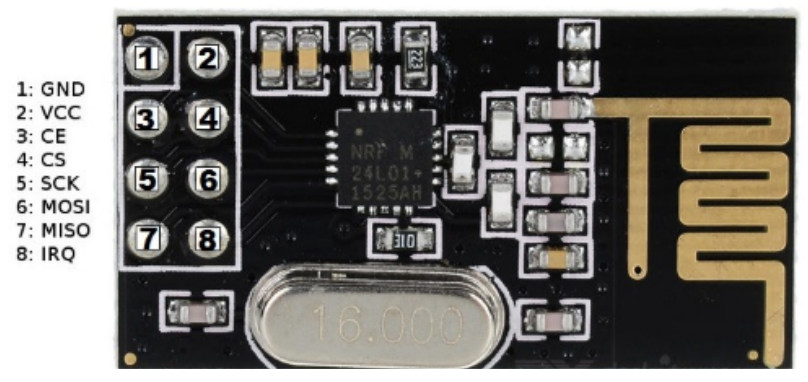

Şekil 2. nRF24L01 modülü

Figure 2. nRF24L01 module

Ölçümü yapılan sistemden alınan gerilim, akım, güç ve enerji değerleri radyo dalgaları vasıtası ile alıcı (bilgisayar) tarafinda bulunan diğer nRF24L01 modülüne gönderilmektedir. nRF24L01'in bilgi yaprağındaki özelliklere göre açık alanda $1 \mathrm{~km}$ mesafeden ölçüm sonuçları alınabilmektedir. $\mathrm{Bu}$ modül için haberleşme protokolü olarak SPI kullanılmıştır. Çünkü SPI haberleşmede kullanılan MOSI, MISO, SCK ve SS olmak üzere 4 bağlantı vardır. Bunlardan MOSI ve MISO veri alışverişi, SCK saat sinyali ve SS uydu (slave) cihazı seçmek için kullanılmaktadır. nRF24L01'lerden biri uydu cihaz olarak çalışmaktadır. Uydu cihazı kontrol eden cihaz ise ana (master) cihazdır. $\mathrm{Bu}$ durumda Arduino veya başka bir ișlemci ise ana cihaz olmaktadır. Buna göre Arduino'nun başka bir işlemci ile kullanılacağı zaman SPI bacakları ile bağlanması gerekmektedir [7, 8].

Alıcı modül ile alınan değerler, ikinci bir mikroişlemci üzerinden bilgisayara aktarılmaktadır. Alınan bu değerler ise bilgisayar ekranında; belirlenen algoritma doğrultusunda C\# programı ile hazırlanan sade ve kullanicı dostu bir arayüzde gösterilmektedir. Bu programın seçilmesinin nedeni; Net Framework platformu için hazırlanmış tamamen nesne yönelimli bir yazılım dili ve en popüleri olmasıdır. Yani nesneler önceden sinıflar halinde yazilı olup programciya sadece o nesneyi sürüklemek ve sonrasında nesneyi amaca uygun çalıştıracak kod satırlarını yazmak kalmaktadır [11]. Bu da tasarlanan sistemin istenilen şekilde yapılandırılmasına imkan sağlamaktadır.

Yük olarak hem statik yük tipi olarak potansiyometre hem de dinamik yük tipi olarak DC motorlu fan kullanılmıştır. Ayrıca; bu ölçüm sisteminde, üzerinde ölçüm yapılacak yük üzerindeki akım ve gerilim değerleri kullanıcı tarafindan belirlenen sınır değerleri aştığında devreye girecek bir koruma alt sistemi de bulunmaktadır. $\mathrm{Bu}$ çalışma yöntem olarak elektronik donanım tasarımı, arayüz geliştirme, haberleşme ve yazılım olmak üzere birçok konuyu içinde barındırmakta olup aynı zamanda çok disiplinli mühendislik uygulamasıdır.

\section{Bulgular ve Tartışma}

Ölçü aletlerinin çalışabilmesi için bir güç kaynağına ihtiyaçları vardır. $\mathrm{Bu}$ el tipi wattmetrelerde olduğu gibi bir batarya grubu ile sağlanabilir. Ayrıca, tasarımı yapılan wattmetrenin pano tipi olması ve çevre birimlerde DC enerji ile çalışan başka ölçüm aletleri, analiz cihazları, denetleyiciler, koruma cihazları vb. bulunması sebebiyle aynı DC baradan beslenebilmektedir. Böylelikle prototipi yapılan bu cihaz; sektördeki mevcut ölçüm yerlerine ve gelecekte ihtiyaç olacak yerlere ek bir düzenleme gerektirmeksizin monte edilebilecektir. Çalışma esnasında bu harici güç kaynağ1 bir adaptör ile sağlanmıștır. Yapılacak tüm aşamaları gösteren algoritma ise Şekil 3'te gösterildiği gibidir. Şekle göre; işlemci başlatıldığında sensörden sonuçları alarak eğer bağlantı yoksa "Başla" komutuna dönecektir. Bağlantı varsa işlemciye sonuçlar iletilecek, güç 


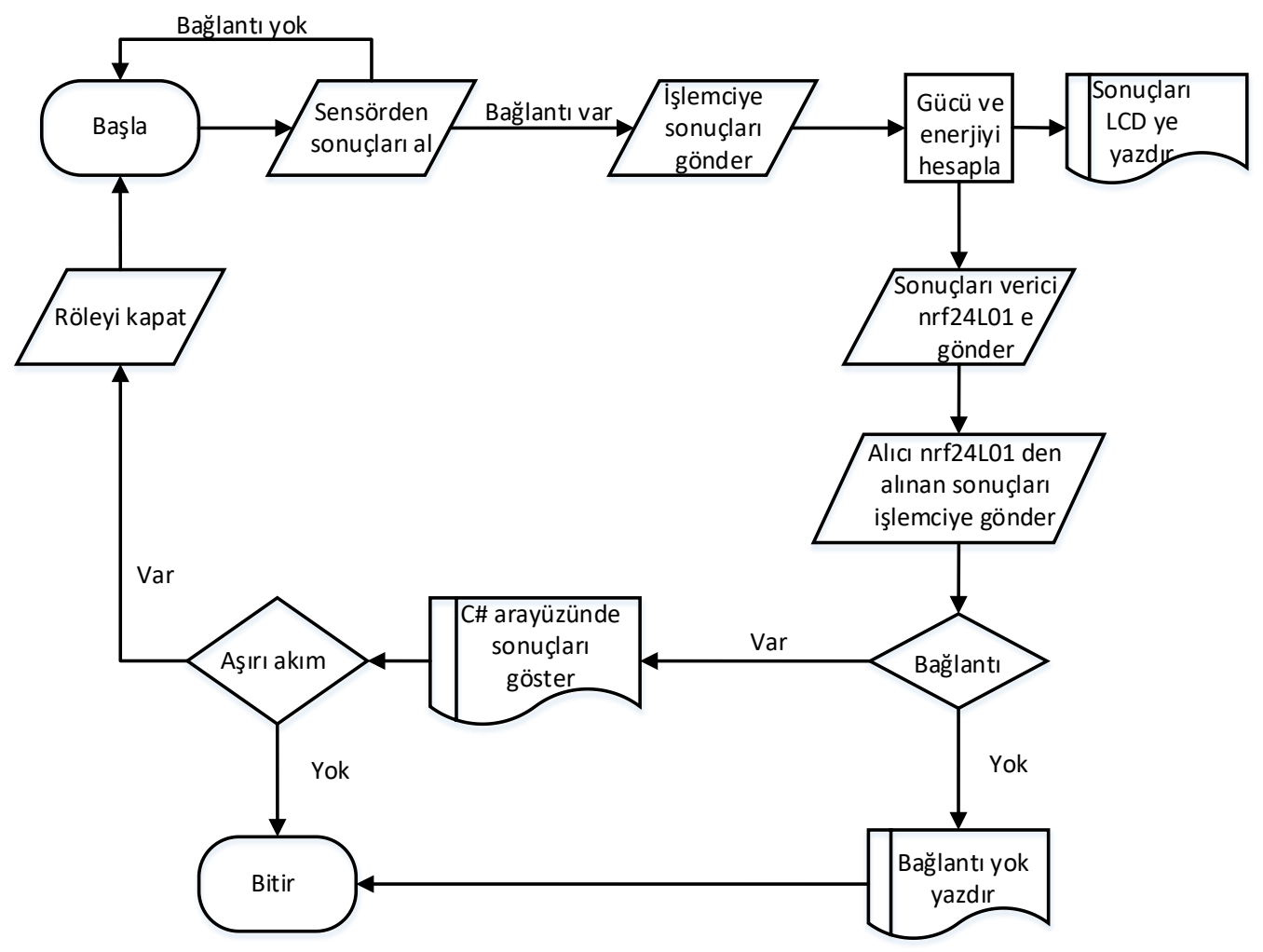

Şekil 3. Algoritma

\section{Figure 3. Algorithm}

ve enerji hesaplanarak LCD'ye yazdiracaktır. Alınan sonuçlar vericiye iletilecek, alıcı nRF24L01'den alınan sonuçlar ise uydu işlemciye iletilecektir. Bağlantı yoksa "Bağlantı yok" yazdırılacak ve işlem bitirilecektir. Bağlantı varsa, kullanıcı arayüzünde sonuçlar gösterilecek ve işlem bitirilecektir.

Akım ölçümünün seri bağlantı ile gerilim ölçümünün de paralel bağlantı ile yapılması özelliklerini barındıran INA219 sensörü ile gereken ölçümler tek bir sensörle elde edilmiștir. $\mathrm{Bu}$ iki ölçüm için ayrı ayrı yapı kurulsa idi kullanılacak malzeme fazlalığından dolayı daha fazla alana ihtiyaç duyulacaktı. Bu da ergonomi, maliyet vb. etkenlere olumsuz yansiyacaktır. Genel olarak verici kısım olan yük üzerindeki DC parametrelerin ölçüldüğü ve bilgisayara iletilmek üzere hazırlandığ 4'te gösterilmektedir. Verici kısımdan iletilen değerler; maksimum 1000 metre uzakl1kta bulunabilecek bilgisayar üzerindeki alıcı (uydu) işlemciye gönderilmektedir.

Uzaktaki bilgisayara iletilen değerler Şekil 5'te görüldüğü gibi hem işlemcinin arayüzünde hem de Şekil 6'daki gibi hazırlanan kullanıcı arayüzünde okunmaktadır. Hazırlanan arayüzde
"Bağlan", "Bağlantıyı kes", "Kullanılan port" ve "Ölçülen değerler" gibi bölümler bulunmaktadır. Kullanilan portlar ihtiyaca göre değiştirilebilmektedir. Operatör bu arayüz üzerinden sistemin ihtiyaçlarına göre akım ve gerilim sinır değerlerini uzaktan değiştirebilmektedir. Şekil 6b'de görüldüğü gibi belirlenen sınır değerler aşıldığında arayüzde uyarı görülmekte ve multimetreyi devre dışı birakan koruma sistemi devreye girmektedir.

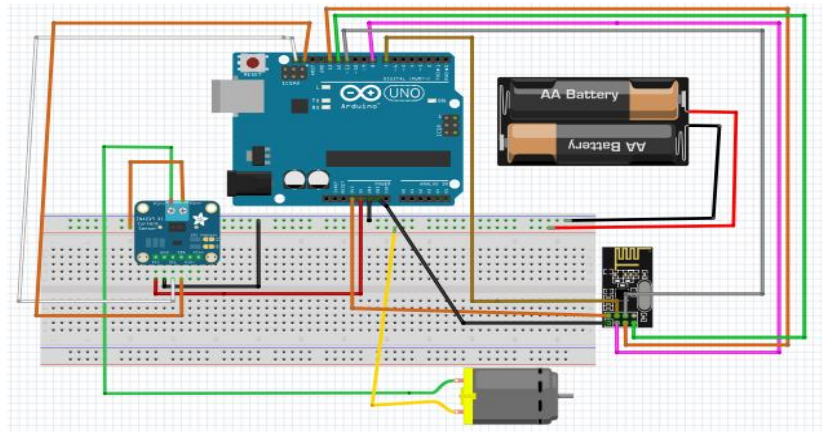

Şekil 4. Verici kısım şeması

Figure 4. Transmitter part scheme

Aynı DC barada bağlı farklı akımda çalışan diğer cihazların çalışmasına engel olmamak için 
ölçü aleti devre dışı edilmektedir. Ancak aynı akım değerleri altında çalışan cihazlar olması durumunda tasarlanan wattmetre ile ek bir koruma cihazına gerek duyulmadan ana hat açılarak da sistemin koruması yapılabilir. Böylelikle kullanılacağı sisteme göre yapılandırılabilir bir cihaz da elde edilmiştir.

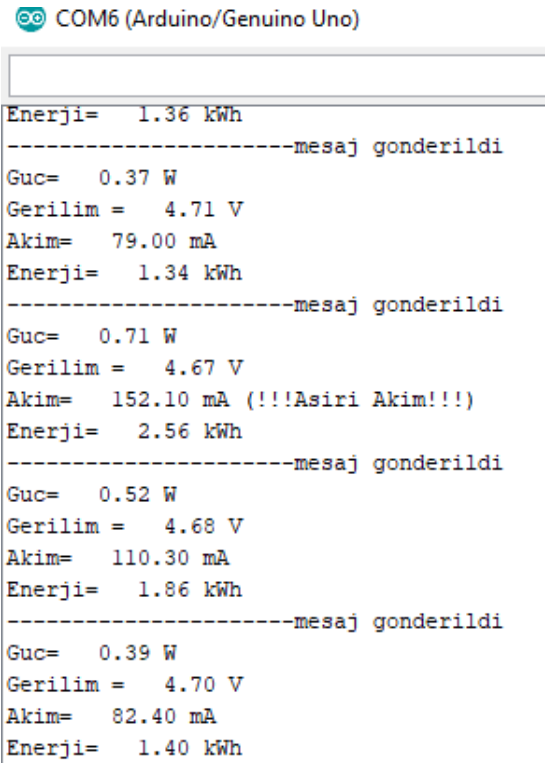

Şekil 5. Arduino arayüzünden alınan sonuçlar

\section{Figure 5. Results from Arduino interface}

Prototipi yapılan ürüne ait ayrıntılı görseller Şekil 7a ve 7b'de verilmiştir. Şekil 7a cihazın iç kısmını, Şekil $7 b$ ise bütün donanımların bir araya getirilerek kutulanmış halini ve çalışır halini göstermektedir. Cihaz kutu halinde yapılmış olup pano tipi olarak da modifiye edilebilmektedir. Son olarak bu makale kapsamında tasarımı yapılan ve üretilen prototipin mevcut ticari ürünlerle karşılaştırmalı özellikleri Tablo 1'de verilmiştir. Görüldüğü üzere tasarlanan DC wattmetre hem daha fazla özelliğe sahip hem de daha ekonomiktir. Fiyat konusunda seri üretim yapıldığında fiyatının daha da düşecek olması ürünü daha cazip hale getirecektir.
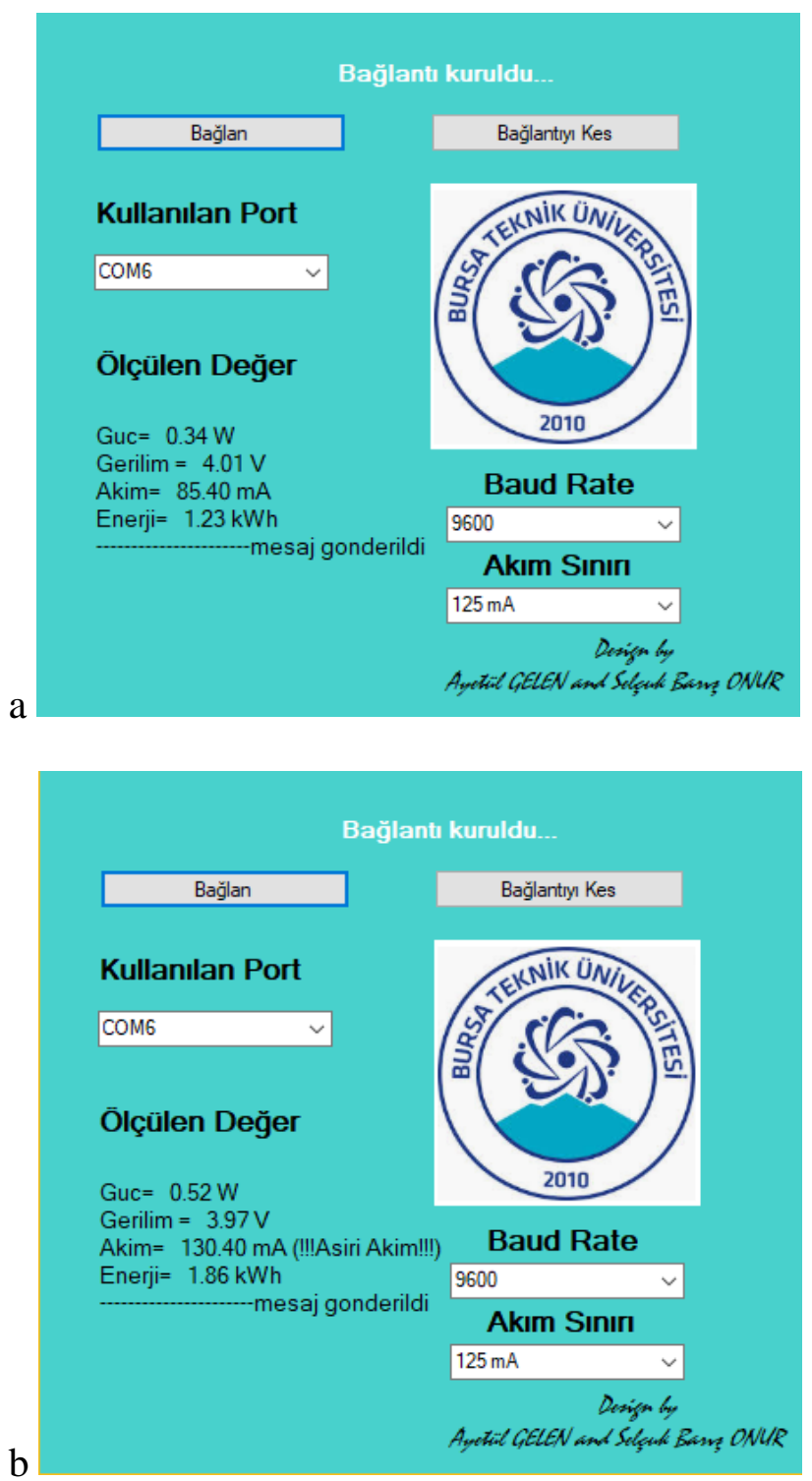

Şekil 6. PC kullanıcı arayüzü (a) Normal durum (b) Aşırı akım durumu

Figure 6. PC user interface a) Normal state b) Overcurrent state 

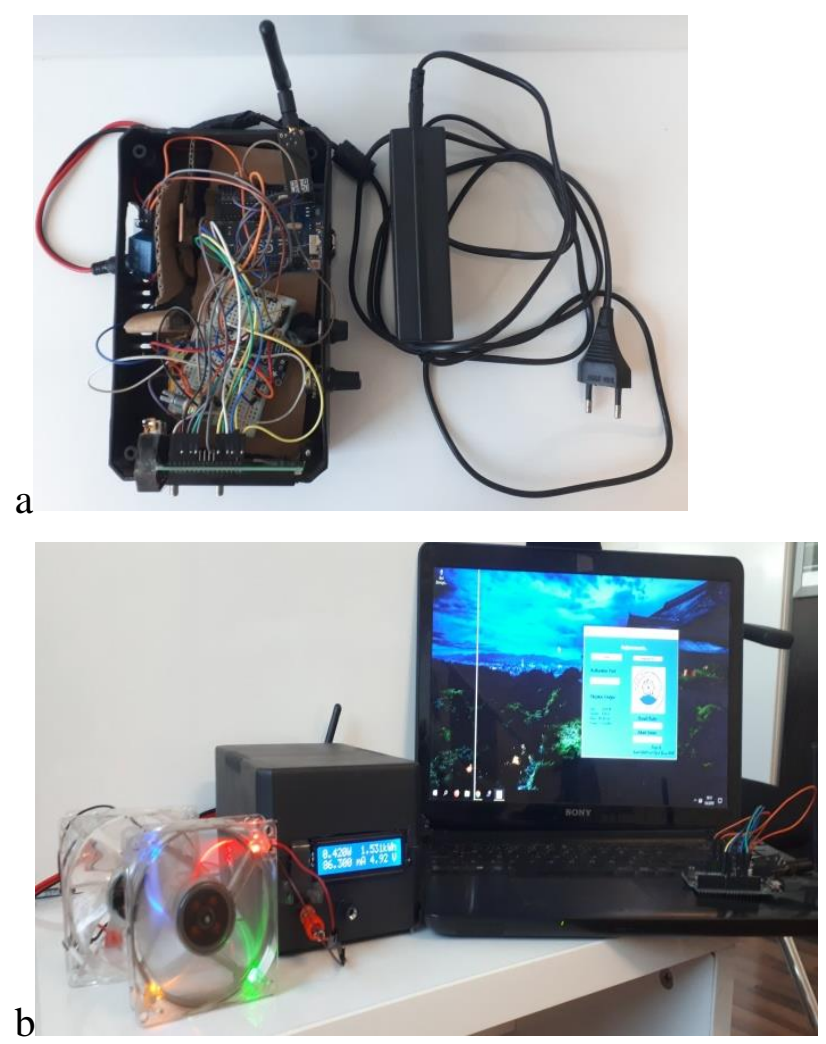

Şekil 7. (a) Cihazın iç kısmı (b) Prototip ürünün son hali ve kullanımı

Figure 7. a) Interior of device b) Final version of prtotype product and its usage

\section{Sonuçlar}

$\mathrm{Bu}$ çalışmanın çıktısı olan DC wattmetre ile ölçülen değerler radyo sinyalleri vasitası ile bilgisayara kablosuz olarak aktarılmakta olup çalışmanın en önemli yenilik unsurunu teşkil etmektedir. Bilgisayar üzerinden kullanıcı; arayüz vasıtası ile cihazın yanına gitmeden ölçüm sonuçlarını gerçek zamanlı olarak görebilmektedir. Ayrıca cihazı ve isterse sistemi arıza vb. istenmeyen durumlarda devre dışı birakabilmektedir. $\mathrm{Bu}$ da ekstra bir koruma sağlamaktadır. Böylelikle 4. sanayi devriminin gerektirdiği gibi uzaktan gözlenebilen, kullanıcı arayüzü olan, minimum insan gücü gerektiren ve sanayide çok kullanılabilecek bir ölçüm cihazı tasarımı yapılmıştır. Prototip ürün ticari muadillerine göre daha ekonomiktir. Gelecek çalışma olarak prototipi yapılan cihazın yüksek güçleri ölçebilecek hale getirilmesi planlanmaktadır.

\section{Tablo 1. Karşılaştırmalı ürün analizi}

Table 1. Comparative product analyses

\begin{tabular}{lccc}
\hline Özellikler & $\begin{array}{c}\text { Ticari ürün-1 } \\
\text { (Peacefoir-PZEM-031) }\end{array}$ & $\begin{array}{c}\text { Ticari ürün-2 } \\
\text { (A (200200) 680-Watt Metre) })\end{array}$ & Tasarlanan cihaz \\
\hline Gerilim ve akım ölçümü & $\sqrt{ }$ & $\sqrt{ }$ & $\sqrt{ }$ \\
Güç ölçümü & $\sqrt{ }$ & $\sqrt{ }$ & $\sqrt{ }$ \\
Enerji ölçümü & $\sqrt{ }$ & $\sqrt{ }$ & $\sqrt{ }$ \\
Yakın mesafeden ölçüm & $\sqrt{ }$ & - & $\sqrt{ }$ \\
Kullanıcı arayüzü & - & - & $\sqrt{ }$ \\
Kablosuz haberleşme ve erişim & - & - & $\sqrt{ }$ \\
Endüstri 4.0 uyumu & - & $89 \mathrm{TL}$ & $68 \mathrm{TL}$ \\
Akım ve gerilim sınırlandırmalı koruma & - & 255 TL & \\
Fiyat & &
\end{tabular}




\section{Kaynaklar}

[1] D. Gorecky, M. Schmitt, M. Loskyll and D. Zühlke, "Human-machine-interaction in the Industry 4.0 Era", 12. IEEE International Conference on Industrial Informatics, Porto alegre, Brasil, 89-294, (2014).

[2] G. Wijeweera, C. Shafai and A. Rajapakse, "Measuring Power system Voltage Remotely using Micromachined Electric Field Sensor", 1. IEEE Microsystems and Nanoelectronics Research Conference, Canada, 209-212, (2008).

[3] A. Cataliotti, V. Cosentino, D. Di Cara, A. Lipari, S. Nuccio and C. Spataro, "A PC-Based wattmeter for accurate measurements in sinusoidal and sistorted conditions: Setup and experimental characterization", IEEE T. Instrum. Meas., vol. 61, no 5, pp. 1426-1434, May 2012.

[4] L. D. Jovanoviç, “A novel TDM-based high-precision wattmeter", IEEE T. Instrum. Meas., vol. 66, no 6, pp. 1083-1088, June 2017.

[5] F. DeWolf and R. N. Michael, "Measurement of input power of DC motors operated using rectifier power supplies and choppers", IEEE T. Ind. Appl., vol. IA16, no 3, pp. 372-378, May/June 1980.
[6] S. B. Onur and A. Gelen, "Elektronik Sistemlerdeki DC Parametrelerin RF ile İzlenmesi”, 2. Geleceğin Mühendisleri Uluslararası Öğrenci Sempozyumu, ÖZET, 96, Zonguldak, Türkiye, (2018).

[7] Ç. Taşdemir, Arduino (10. bs.), İstanbul: Dikeyeksen Yayınevi, 2016.

[8] S. D. Saygıl1, Projelerle Arduino (6. bs.), İstanbul: Abaküs Yayınevi, 2015.

[9] Anonim, (10 Nisan 2018). [Online]. Erişim adresi: https://www.adafruit.com/product/904.

[10] Nordic Semiconductor, nRF24L01 datasheet, URL: https://www.sparkfun.com/datasheets/Components/n RF24L01_prelim_prod_spec_1_2.pdf (Erişim zaman1: Nisan, 10, 2018)

[11] S. Algan, Her Yönüyle C\# (22. bs.). İstanbul: Pusula Yayınc1lik, 2003. 